\title{
Reduced Emissions from Deforestation and Forest Degradation (REDD): Why a Robust and Transparent Monitoring, Reporting and Verification (MRV) System is Mandatory
}

\author{
Daniel Plugge ${ }^{1}$, Thomas Baldauf ${ }^{2}$ and Michael Köhl' ${ }^{1,2}$ \\ Institute for World Forestry \\ 1 University of Hamburg \\ ${ }^{2}$ von Thünen-Institute, Federal Research Institute for Rural Areas \\ Forestry and Fisheries \\ Germany
}

\section{Introduction}

The reduction of emissions from deforestation and forest degradation (REDD) was approved at the $16^{\text {th }}$ session of the Conference of the Parties of the UNFCCC in Cancún in 2010 as an eligible action to prevent climate change and global warming in post-2012 commitment periods.

REDD assigns a financial value to the carbon stored in forests. In order to generate benefits from REDD countries need to implement sound systems for monitoring, reporting and verification (MRV) of carbon stocks. The mere reporting of point estimates such as carbon stocks or carbon stock changes is not sufficient, unless the associated uncertainties are specified. Sampling and non-sampling errors influence the reliability of estimated activity data and emission factors, and thus affect the potential to generate benefits from implementing a REDD-regime. Uncertainties are addressed by the principle of conservativeness that requests the reporting of the reliable minimum estimate (RME). The RME constructs a reliability interval around a carbon stock estimate and utilizes the lower bound for reporting and the calculation of benefits.

In this chapter, a framework for calculating accountable emission reductions including assessment errors is developed. Theoretical considerations as well as a simulation study for four selected countries with low to high deforestation and forest degradation rates show that even small assessment errors ( $5 \%$ and less) may offset successful efforts in the reduction of emissions from deforestation and forest degradation. The generation of benefits from REDD renders possible only in situations where a robust and transparent MRV-system is applied that provides a sound approach for the calculation of RMEs.

\section{Background}

According to the United Nations Food and Agricultural Organisation (FAO) forests cover $31 \%$ of the global land area. FAO estimates that the world's forests store 289 gigatonnes (Gt) 
of carbon in their biomass alone (FAO, 2010b). Whilst sustainable forest management, planting or rehabilitation of forests can positively affect forest carbon stocks, deforestation, forest degradation and poor forest management have a negative effect on them. Due to the conversion to other uses or loss through natural causes approximately 13 million hectares of forest disappeared annually in the last decade.

In this context deforestation is generally understood as the direct human-induced conversion of forest land to non-forest land, while forest degradation is according to the Intergovernmental Panel on Climate Change (IPCC) "the direct human-induced long-term loss" of forest carbon stocks in areas which remain forest land (IPCC, 2003).

In 2005 Papua New Guinea together with 8 other developing countries proposed the new agenda item "reducing emissions from deforestation in developing countries" at a national

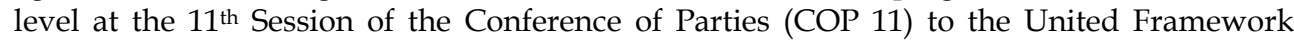
Convention on Climate Change (UNFCCC). The proposal aimed at the acknowledgement of reducing emissions from deforestation and forest degradation in developing countries (REDD) as a mitigation option for those countries. The idea of REDD was later on extended beyond the mere conservation of forests in order to include additional aspects of biodiversity, sustainable management of forests and enhancement of forest carbon stocks, called REDD+1. At the $16^{\text {th }}$ session of the Conference of the Parties of the UNFCCC in Cancún in 2010 the REDD mechanism was approved as an eligible action to prevent climate changes and global warming in post-2012 commitment periods (UNFCCC, 2011).

A country participating in the REDD mechanism of the UNFCCC has to demonstrate substantial capacities for monitoring and accounting emissions from forest carbon stocks. Thus a reliable framework for MRV is vitally required to ensure the integrity and credibility of possible REDD efforts in general. Approaches for MRV as well as potential financing mechanisms for the set-up of appropriate incentives have been widely discussed (Eliasch, 2008; GOFC-GOLD, 2010). IPCC requests the use of the reliable minimum estimate (RME) to address uncertainties associated with the estimation of forest area and carbon stock changes. Even though these uncertainties have a fundamental impact on accountable carbon credits and the cost-benefit ratio, they play only a minor role in the discussions both on political, scientific and operational level.

\subsection{Assessment of emissions from deforestation and forest degradation}

There are five major carbon pools in forests (IPCC, 2003): (1) above-ground biomass, (2) below-ground biomass, (3) dead wood, (4) litter, and (5) soil organic matter. The reduction of emissions from deforestation and forest degradation renders the maintenance of carbon in the living biomass essential. For this reason the most pragmatic monitoring approach is to concentrate efforts on the assessment of the carbon pool "above-ground biomass".

To monitor and report deforestation and forest degradation the assessment of two components is required (IPCC, 2003):

- $\quad$ changes in forest area over time (activity data), and

- $\quad$ changes in the average carbon stock per unit area over time (emission factors).

Assessments at successive occasions or the availability of models that extrapolate data from one point in time to another, allow the estimation of changes. To assess the total loss of forest carbon stock in a given period and area two components have to be considered:

${ }^{1}$ The terms REDD and REDD+ are used synonymously in this text. 
(1) the carbon stock loss on areas that changed from forest land to other land uses in the respective period, and (2) the reduction of average carbon stock in areas that remain forest land. Aiming at the enhancement of the reliability of estimates, the forest area can be subdivided in several categories showing distinct levels of carbon stock changes.

Changes in forest area can be estimated by in-situ surveys or remote sensing techniques. Remote sensing techniques are more cost efficient and result in spatially explicit data. Furthermore, remote sensing data allow for the separation of the total forest area into different homogeneous sub-groups or strata, such as forest types (e.g. broadleaf, tropical moist or tropical dry). The classification of forest areas can be complemented by risk factors that utilize probabilistic approaches for describing the likelihood of changes. Proxies for risk factors can be accessibility, population density or previous intensities of human impacts. In extensive surveys of large areas the use of remote sensing techniques are capable of detecting deforestation patterns. In contrast to deforestation forest degradation does not necessarily lead to an obvious reduction of canopy cover, even under substantial removals of biomass. The detection of forest degradation by remote sensing techniques is far more difficult than the detection of deforestation and provides reliable results only for advanced stages of forest degradation.

Changes in carbon stock can be quantified by various methods. Among others IPCC provides a set of default values for carbon stocks per unit area (IPCC, 2003). However, these may not reflect the true country specific values. Using these default values can result in substantial uncertainties. Country specific data on degradation of distinct forest types or risk classes reduce uncertainties. The most reliable estimates of carbon stock changes are provided by sample based field assessments on successive occasions. Individual trees are measured, and biomass and carbon stock are calculated on plot level. Upscaling procedures are applied to expand plot level data to area related estimates (Köhl et al., 2006; Plugge et al., 2010), resulting in sound and sensitive estimates of changes in forest biomass and degradation activities.

The IPCC Good Practice Guidance (IPCC, 2003) and Guidelines for National Greenhouse Gas Inventories (IPCC, 2006) include recommendations on methods and default values for assessing carbon stocks and emissions. Two approaches for the calculation of changes in average carbon stock per unit area are proposed (IPCC, 2003, 2006):

1. the stock difference method makes reference to traditional forest resource assessments and calculates changes in average carbon stock per unit area as the difference between carbon stock at time 2 and time 1 , and

2. the gain-loss method builds on the understanding of carbon uptake by forests (tree growth) and carbon release by anthropogenic activities such as timber removals, fuelwood gathering, sub-canopy fires or grazing.

The IPCC-guidelines provide three tiers of detail for reporting in order to consider the substantial differences between countries regarding the capacities and implemented MRVsystems for carbon stock changes. Moving to higher tiers increases the complexity and cost of the utilized MRV-systems but results in a higher reliability of estimates.

\subsection{Uncertainties}

The Subsidiary Body for Scientific and Technological Advice (SBSTA) is concerned with methodological issues with reference to the implementation of REDD as a mitigation option in the context of UNFCCC and stated in its $28^{\text {th }}$ session that "means to deal with 
uncertainties in estimates aiming to ensure that reductions in emissions or increases in removals are not overestimated" need to be further considered (UNFCCC, 2008), to ensure the credibility of estimated emissions and removals from deforestation and forest degradation. In general any assessment and estimation methodology is intrinsically associated with uncertainties. In REDD those are mainly linked to the assessment of deforestation and forest degradation areas (activity data, AD) and the carbon stock changes in those areas (emission factors, EF).

Two major error types exist regarding the estimation of AD and EF: sampling errors and non-sampling errors (Lessler \& Kalsbeek, 1992). The former arise from inferring from a subset (i.e. the sample) of the population to the whole population. The size of the sample and the survey design can be used to control the size of sampling errors. The latter encompass all other sources of errors involved in a survey. This can be measurement errors, calculation errors, classification errors, incorrect application of definitions, errors arising from the application of functions and models, or frame errors (i.e. the sample population is different from the target population). Precision, accuracy, and bias are means to quantify different types of errors (Köhl et al., 2006).

To quantify the uncertainty of estimates the IPCC suggests the $95 \%$-confidence interval (IPCC, 2003, 2006). In statistical terminology the confidence interval is related to sampling errors only. A useful measure is the Mean Square Error (MSE), that combines sampling errors with the square of the bias. For unbiased estimators MSE and precision are asymptotically identical. In order to quantify all error sources associated with an estimate the total survey error (Kish, 1965) or error budgets (Gertner \& Köhl, 1992) can be applied.

\subsection{Monitoring changes over time}

Quantifying AD requires estimates of forest area changes over time. The use of remote sensing techniques implicates that the uncertainty related to the estimation of changes between two points in time is strongly affected by classification accuracies at both occasions and the magnitude of the respective changes. Fuller et al. (2003) discuss the measurement of landcover change over time and present a statistical approach to quantify the reliability of change estimates. They show that for 10-class maps the accuracy at both times needs to be $99 \%$ to detect a smaller than $20 \%$ change with a $90 \%$ reliability. Fuller et al. (2003) conclude that the "measurement of small to medium scale changes over large areas requires levels of precision in mapping which are near impossible to achieve with satellite image classification alone".

Another critical issue is the ability to detect forest degradation by remote sensing data. Especially in heterogenic vertical stand structures and contiguous canopy covers, e.g. in natural forests in the tropics and subtropics, forest degradation can only be detected, when the formerly closed canopy cover is dissolved (Fig. 1).

Quantifying EFs is realized by in-situ assessments in forest stands, following the rules of probabilistic sampling theory. Above-ground volume or biomass figures are used to estimate the carbon stock of trees. However, these figures cannot be directly assessed on standing trees and have to be estimated via volume or biomass functions, which utilize tree measurements such as diameters, tree heights or crown parameters as independent variables. Biomass expansion factors (BEF) expand volume estimates to biomass estimates, while biomass estimates are transferred into carbon stock estimates by applying biomasscarbon conversion factors. The conversion factors depend on the wood density of the respective tree species and tree components. 


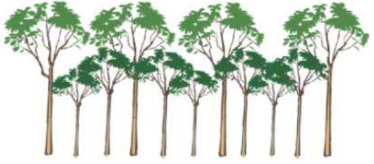

Biomass Stock time 1

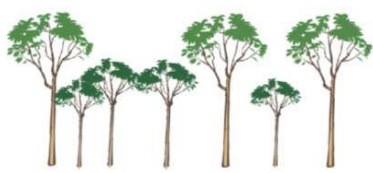

Biomass Stock time 2 Not detectable by passive remote sensing

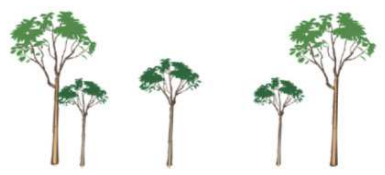

Biomass Stock time 3 Detectable by passive remote sensing

Fig. 1. Different status of forest degradation and potential of detection by passive remote sensing techniques (Baldauf et al., 2009)

Including measurement errors and function errors, the EF-estimates are subject to multiple error sources. Highly problematic are frame errors, as assessments of a limited set of field plots (i.e. the sample population) may not be representative for the entire domain of tree species, forest types, ecosystem regions and disturbance levels within a country (i.e. the target population) (Houghton et al., 2001; Nogueira et al., 2008). Figures for above-ground biomass, which show a large range of variability, are presented by IPCC (IPCC, 2003). For example, the possible range of values in wet tropical forests covers $34 \%$ to $248 \%$ of the average, showing that currently a high level of uncertainty is associated with the quantification of above-ground biomass stock.

\subsection{The principle of conservativeness}

In order to "address the potential incompleteness and high uncertainties of REDD estimates" the principle of conservativeness was proposed by Grassi et al. (2008). UNFCCC has already included this principle in several documents, e.g. for afforestation and reforestation activities under the Clean Development Mechanism (CDM) (UNFCCC, 2006a, 2006b).

The completeness principle depends on "the processes, pools and gases that need to be reported and on the forest-related definitions" (Grassi et al., 2008). In REDD the quantification of carbon stock changes needs to consider both, uncertainties and incompleteness. To address uncertainties the Reliable Minimum Estimate (RME) is suggested by the IPCC-Good Practice Guidance in the context of the assessment of changes in soil carbon. The RME serves as a surrogate for the lower bound of a confidence interval and is the minimum quantity to be expected with a given probability (Dawkins, 1957).

In the context of carbon stock change assessments the principle of the RME has to be expanded from a sole sampling error perspective to the concept of total survey errors. A conservative RME qualifying for accounting can be calculated as the difference between the lower bound of the error interval at the reference period (time 1) and the upper bound of the error interval at the assessment period (time 2). While error intervals take into account the total survey error, confidence intervals include only sampling errors. Thus error intervals are wider than confidence intervals and result in notably smaller accountable emission reduction. 
For countries that are still in the readiness phase and have not implemented a sound REDD inventory concept so far, the principle of conservativeness is a wise recommendation. However, in a situation where a country is maintaining or only slightly decreasing its forest area, the principle of conservativeness might lead to counterproductive results. The RME of the estimated forest area at time 1 would be (considerably) lower as the higher RME of the estimated (unchanged) forest area at time 2, thus a forest area loss would need to be reported. Or, in other words, if the area of afforestation activities has the same size as the difference between the RMEs at time 1 and time 2, a country without any deforestation activities would be able to report only an unchanged forest area under the principle of conservativeness. Introducing a REDD-regime under these conditions would not be beneficial for such a country.

\section{Data and methods}

\subsection{Global Forest Resources Assessment}

For more than five decades the state of the world's forests has been monitored by FAO, with the intention to provide information "to policy-makers, to international negotiations, arrangements and organizations related to forests and to the general public" on a global scale (FAO, 2010b).

Earlier forest resources assessments focused mainly on the provision of information on the productive forest functions (i.e. attributes such as basal area, timber volume, wood assortments, timber value or increment). Nowadays FAOs forest resources assessments have a much wider scope and cover the rising demand for more detailed information. The Global Forest Resources Assessment 2010 (FAO, 2010a) is the most comprehensive assessment to date, incorporating the seven thematic elements of sustainable forest management:

- $\quad$ extent of forest resources;

- forest biological diversity;

- forest health and vitality;

- productive functions of forest resources;

- protective functions of forest resources;

- $\quad$ socio-economic functions of forests;

- legal, policy and institutional framework. (FAO, 2010b)

The Global Forest Resources Assessment 2010 (FRA 2010) provides information for four points in time, i.e. 1990, 2000, 2005 and 2010, and the respective trends (FAO, 2010b). In the scope of this study we decided to analyze FRA data from the years 1990, 2000 and 2010. Data from the year 2005 were omitted in order to simulate a reference period from 1990 to 2000 and an assessment period from 2000 to 2010, both of equal length (10 years).

Information needs for REDD on forest area changes (AD) and carbon stock changes in those areas (EF) can be satisfied by focusing on the FRA's first thematic element. Table 1 shows country specific data on forest resources for four countries that hold small to large forest areas and show low to high deforestation rates.

Activity data for these countries can be calculated as the difference in forest area between two successive points in time. The ratio of total forest carbon stock and total forest area gives information on the emission factors. Table 2 presents the annual mean values of activity data for the anticipated reference (1990 to 2000) and assessment period (2000 to 2010) and the per hectare carbon stock for each point in time. 
Reduced Emissions from Deforestation and Forest Degradation (REDD): Why a Robust and Transparent Monitoring, Reporting and Verification (MRV) System is Mandatory

\begin{tabular}{|c|c|c|c|c|c|c|c|}
\hline & & \multicolumn{3}{|c|}{ Forest area (1000 ha) } & \multicolumn{3}{c|}{ Carbon stock (Mt) } \\
\hline Country/Year & $\begin{array}{c}\text { Category } \\
*\end{array}$ & 1990 & 2000 & 2010 & 1990 & 2000 & 2010 \\
\hline Costa Rica & LFLD & 2,564 & 2,376 & 2,605 & 233 & 217 & 238 \\
\hline Indonesia & HFHD & 11,8545 & 99,409 & 94,432 & 16,335 & 15,182 & 13,017 \\
\hline Malaysia & HFMD & 22,376 & 21,591 & 20,456 & 2,822 & 3,558 & 3,212 \\
\hline Madagascar & LFLD & 13,692 & 13,122 & 12,553 & 1,778 & 1,691 & 1,626 \\
\hline
\end{tabular}

Table 1. Country specific data on forest resources (from FRA 2010) (FAO, 2010a); HF = high forest area, $\mathrm{LF}=$ low forest area, $\mathrm{HD}=$ high deforestation rate, $\mathrm{MD}=$ medium deforestation rate, $\mathrm{LD}=$ low deforestation rate, ${ }^{*}$ according to Griscom et al. (2009)

\begin{tabular}{|c|c|c|c|c|c|c|}
\hline & & \multicolumn{2}{|c|}{$\begin{array}{c}\text { Forest area change } \\
(1000 \mathrm{ha} / \mathrm{y})\end{array}$} & \multicolumn{3}{c|}{$\begin{array}{c}\text { Carbon stock } \\
(\mathrm{t} / \mathrm{ha})\end{array}$} \\
\hline Country/Year & Category* & $1990-2000$ & $2000-2010$ & 1990 & 2000 & 2010 \\
\hline Costa Rica & LFLD & -19 & 23 & 90.87 & 91.33 & 91.36 \\
\hline Indonesia & HFHD & $-1,914$ & -498 & 137.80 & 152.72 & 137.85 \\
\hline Malaysia & HFMD & -79 & -114 & 126.12 & 164.79 & 157.02 \\
\hline Madagascar & LFLD & -57 & -57 & 129.86 & 128.87 & 129.53 \\
\hline
\end{tabular}

Table 2. Country specific data on annual forest area change and per hectare carbon stock; $\mathrm{HF}=$ high forest area, $\mathrm{LF}=$ low forest area, $\mathrm{HD}=$ high deforestation, rate $\mathrm{MD}=$ medium deforestation rate, $\mathrm{LD}=$ low deforestation rate, ${ }^{*}$ according to Griscom et al. (2009)

The data given in Table 1 and Table 2 are used as the input data for the simulation study described below. The layout of the simulation study follows the principles described in Köhl et al. (2009).

\subsection{Accountable emission reductions}

For the generation of benefits from a REDD regime possible reductions of emission from deforestation and forest degradation must be identified. Therefore a reference must be defined, against which the actual emissions from deforestation and forest degradation are set off. In the nomenclature of REDD this reference emission level is called baseline. Different types of baselines are still subject to political and scientific discussions (Griscom et al., 2009) as the choice for a specific baseline may be of advantage or disadvantage to a single country. There are simple baseline approaches like historical baselines, based on annual deforestation areas in past periods, to more complex approaches that project a future deforestation scenario by integrating numerous variables, including key socioeconomic, technological, and political factors that drive deforestation (Eliasch, 2008).

The data on carbon stock in forests in the Global Forest Resources Assessment (FAO, 2010a) appears to be distorted by inconsistent estimation approaches for different points in time, which add an unknown amount of uncertainty to the values presented. For example, the carbon stocks presented for Malaysia increase by 30 percent between 1990 (126.12 t/ha) and 2000 (164.79 t/ha), while showing a more reasonable decrease by 5 percent between 2000 and 2010 (157.02 t/ha). The values for carbon stock development in forests shown in Table 2 do not include the underlying level of reliability which needs to be taken into account in the 
development of baselines. Therefore, we decided to use a business-as-usual scenario for the construction of the baseline that takes into account the forest area development only. The reference period for this scenario is defined as the period $1990-2000$.

$$
\Delta_{\mathrm{REF}}=\left(A_{\mathrm{t} 1}-A_{\mathrm{t} 0}\right) / A_{\mathrm{t} 1}
$$

where

$\Delta_{\mathrm{REF}}=$ proportional change of forest area between $t_{0}$ and $t_{1}, \Delta_{\mathrm{REF}}=\{-1.1\}$, where negative values indicate a decrease of the forest area, and positive values an increase, e.g. by afforestation or forest growth.

$\mathrm{t}_{0}=$ time 0 (i.e. 1990)

$t_{1}=$ time 1 (i.e. 2000)

$\mathrm{A}_{\mathrm{t} 0}=$ Forest area at $\mathrm{t}_{0}$

$\mathrm{A}_{\mathrm{t} 1}=$ Forest area at $\mathrm{t}_{1}$

The baseline itself is a mere proportional prolongation of the development of the carbon stocks from the reference period to the assessment period. Therefore we anticipate that the same proportional change holds for forest area and for carbon stock.

$$
\Delta_{\mathrm{REF}}=\Delta_{\mathrm{BL}}
$$

where

$\Delta_{\mathrm{BL}}=$ proportional area change between $t_{0}$ and $t_{1}$ according to the baseline, $\Delta_{\mathrm{BL}}=\{-1.1\}$, where negative values indicate a decrease of the forest area and positive values an increase of the forest area.

The assessment period is defined as the period between 2000 and 2010. Although REDDincentives have not been implemented, we assume that initiatives and measures other than REDD led to a reduction of deforestation in this period. The carbon stock at the end of the assessment period (i.e. 2010), $\mathrm{C}_{\mathrm{t} 2 \text { real, }}$ has to be compared to the expected carbon stock according to the baseline scenario, $\mathrm{C}_{\mathrm{t} 2 \mathrm{BL}}$. This results in the change of carbon stock, $\mathrm{C}_{\mathrm{t} 2 \mathrm{REDD}}$.

$$
\mathrm{C}_{\mathrm{t} 2 \mathrm{REDD}}=\mathrm{C}_{\mathrm{t} 2 \text { real }}-\mathrm{C}_{\mathrm{t} 2 \mathrm{BL}}
$$

where

$\mathrm{C}_{\mathrm{t} 2 \mathrm{REDD}}=$ difference between expected carbon stock according to the baseline and the real carbon stock at time 2

$\mathrm{C}_{\mathrm{t} 2 \mathrm{BL}}=$ expected carbon stock at $\mathrm{t}_{2}$ according to the baseline

$\mathrm{C}_{\mathrm{t} \text { real }}=$ real carbon stock at $\mathrm{t}_{2}$

Emission reductions are accountable as long as $C_{t 2 R E D D}$ has a value $>0$. Whenever $C_{t 2 R E D D}$ is $\leq 0$ no emission reductions qualify for accounting. $\mathrm{C}_{\mathrm{t} 2 \mathrm{REDD}}$ can also be given as a function of $\mathrm{C}_{\mathrm{t} 1}$ and its proportional change indicated by the baseline, $\Delta_{\mathrm{BL}}$, on the one hand and $\mathrm{C}_{\mathrm{t} 2 \text { real }}$ on the other hand.

$$
\begin{aligned}
\mathrm{C}_{\mathrm{t} 2 \text { REDD }} & =\mathrm{C}_{\mathrm{t} 2 \text { real }}-\mathrm{C}_{\mathrm{t} 2 \mathrm{BL}} \\
& =\mathrm{C}_{\mathrm{t} 2 \text { real }}-\mathrm{C}_{\mathrm{t} 1}+\left(\mathrm{C}_{\mathrm{t} 1} \Delta_{\mathrm{BL}}\right) \\
& =\mathrm{C}_{\mathrm{t} \text { 2real }}-\mathrm{C}_{\mathrm{t} 1}\left(1+\Delta \Delta_{\mathrm{BL}}\right)
\end{aligned}
$$


The amount of accountable emission reductions is not only subject to the realized reduction of emissions from deforestation and forest degradation at time 2, but depends on the respective total error $\left(E_{t 2}\right)$ associated with the estimation of $C_{t 2 r e a l}$ as well. Equations (3) and (4) do not incorporate $E_{t 2}$. $C_{t 2 R M E}$ is taking into account the total error at the end of the assessment period $\left(\mathrm{E}_{\mathrm{t} 2}\right)$ and relates it to $\mathrm{C}_{\mathrm{t} 2 \text { real }}$.

$$
\mathrm{C}_{\mathrm{t} 2 \mathrm{RME}}=\mathrm{C}_{\mathrm{t} 2 \mathrm{real}}\left(1-\mathrm{Et}_{2}\right)
$$

where

$\mathrm{C}_{\mathrm{t} 2 \mathrm{RME}}=$ carbon stock at $\mathrm{t}_{2}$ constrained by the total error

$\mathrm{E}_{\mathrm{t} 2}=$ error of the estimated carbon stock at $\mathrm{t}_{2}, \mathrm{C}_{\mathrm{t} 2 \text { real }}$

To adhere to the principle of conservativeness, $\mathrm{C}_{\mathrm{t} 2 \text { real }}$ has to be replaced by $\mathrm{C}_{\mathrm{t} 2 \mathrm{RME}}$ in equation (4) resulting in a new estimate for the accountable emission reductions, $\hat{C}_{t 2 R E D D}$, that incorporates the total error at the end of the assessment period.

$$
\begin{aligned}
\hat{\mathrm{C}}_{\mathrm{t} 2 \mathrm{REDD}} & =\mathrm{C}_{\mathrm{t} 2 \mathrm{RME}}-\mathrm{C}_{\mathrm{t} 2 \mathrm{BL}} \\
& =\mathrm{C}_{\mathrm{t} 2 \text { real }}\left(1-\mathrm{E}_{\mathrm{t} 2}\right)-\mathrm{C}_{\mathrm{t} 1}(1+\Delta \mathrm{BL})
\end{aligned}
$$

where

$\hat{\mathrm{C}}_{\mathrm{t} 2 \mathrm{REDD}}=$ accountable emission reductions at $\mathrm{t}_{2}$

In equation (6) all components that affect the amount of accountable emission reductions are included. While $\Delta_{\mathrm{BL}}$ shows the business-as-usual scenario for the carbon stock development in a situation where no incentives to reduce deforestation and forest degradation have been applied, $\mathrm{C}_{\mathrm{t} 2 \text { real }}$ assumes that such incentives have been successfully applied. The total error affecting the accountable emission reductions $\left(\mathrm{E}_{\mathrm{t} 2}\right)$ is directly linked to the implemented MRV-system.

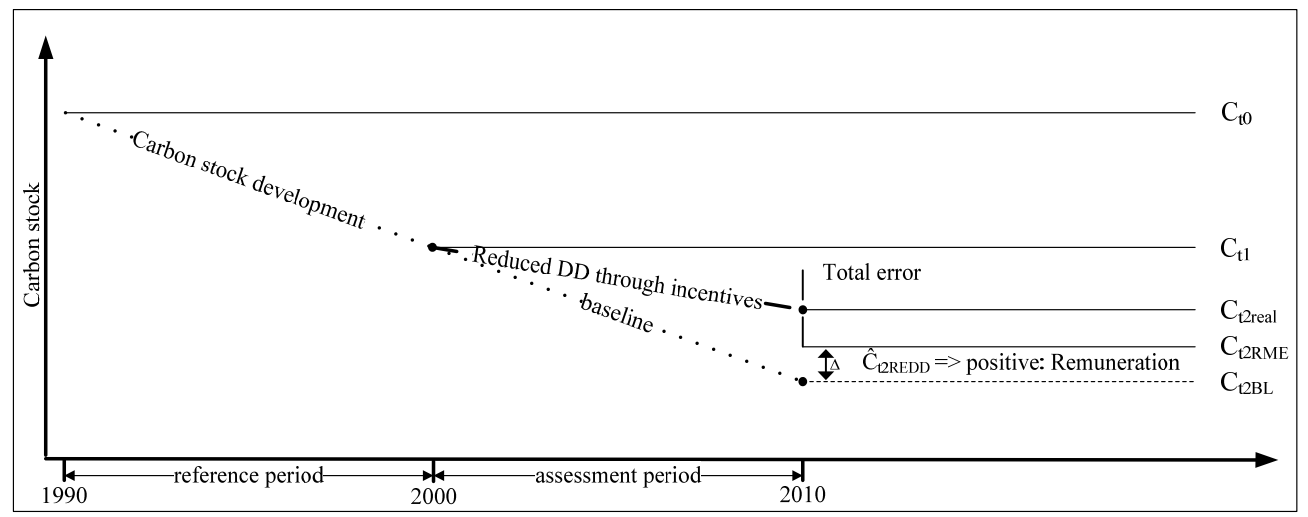

Fig. 2. Reference period (1990 to 2000) and respective carbon stock development for baseline deduction (i.e. difference of carbon stock at $t_{1}, C_{t 1}$, and carbon stock at $t_{0}, C_{t 0}$ ) and relationship of the reduction of deforestation and forest degradation (DD) during the assessment period (2000 to 2010), total error and the respective reliable minimum estimate (RME), and their contribution to the values of the expected carbon stock at time 2 according to the baseline scenario $\left(\mathrm{C}_{\mathrm{t} 2 \mathrm{BL}}\right)$, real carbon stock at time $2\left(\mathrm{C}_{\mathrm{t} 2 \text { real }}\right)$, carbon stock at time 2 qualifying for accounting $\left(\mathrm{C}_{\mathrm{t} 2 \mathrm{RME}}\right)$ and difference of $\mathrm{C}_{\mathrm{t} 2 \mathrm{BL}}$ and $\mathrm{C}_{\mathrm{t} 2 \mathrm{RME}}\left(\hat{\mathrm{C}}_{\mathrm{t} 2 \mathrm{REDD}}\right)$ 
Fig. 2 illustrates the influence of $\mathrm{E}_{\mathrm{t} 2}$ on the accountable emission reductions under a REDD regime. The business-as-usual baseline scenario is derived based on the carbon stock development of the reference period. In this figure the carbon stock resulting from the application of incentives to reduce emissions from deforestation and forest degradation $\left(\mathrm{C}_{\mathrm{t} 2 \text { real }}\right)$ without error components and its associated $\mathrm{RME}\left(\mathrm{C}_{\mathrm{t} 2 \mathrm{RME}}\right)$ including the error components exceed the baseline scenario $\left(\mathrm{C}_{\mathrm{t} 2 \mathrm{BL}}\right)$. In this situation a country would be able to transform the accountable emission reductions $\left(\hat{\mathrm{C}}_{\mathrm{t} 2 \mathrm{REDD}}\right)$ into benefits from emission reductions.

As shown in Fig. 2 accountable emission reductions can only be generated where the real carbon stock in 2010, $\mathrm{C}_{\mathrm{t} 2 \text { real, }}$, is larger than the carbon stock according to the baseline, $\mathrm{C}_{\mathrm{t} 2 \mathrm{BL}}$. In this case $\hat{C}_{\text {t2REDD }}$ becomes positive. However, the amount of the accountable emission reductions generated depends on the error associated with the carbon stock estimates, $\mathrm{E}_{\mathrm{t} 2}$. The functional relationship between $C_{\mathrm{t} 2 \mathrm{BL}}, \mathrm{C}_{\mathrm{t} 2 \text { real }}$ and $\mathrm{E}_{\mathrm{t} 2}$ indicates that the smaller the difference between $\mathrm{C}_{\mathrm{t} 2 \mathrm{BL}}$ and $\mathrm{C}_{\mathrm{t} 2 \text { real, }}$, the smaller $\mathrm{E}_{\mathrm{t} 2}$ has to be in order to generate accountable emission reductions.

\section{Results}

A country that intends to benefit from the adoption of a REDD-regime, needs to proof that deforestation and forest degradation in a current commitment period is smaller than it was in the periods before. Accountable carbon credits, $\hat{\mathrm{C}}_{\mathrm{t} 2 \mathrm{REDD}}$, are obtained by subtracting the real carbon stock at $t_{2}, C_{t 2 \text { real, }}$ from the carbon stock expected under the baseline scenario, $\mathrm{C}_{\mathrm{t} 2 \mathrm{BL}}$, which is derived from past deforestation and forest degradation rates. The larger the difference the more carbon credits are generated.

The approach presented above was utilized for a simulation study that links the calculation of accountable emission reductions with assessment errors. Results are presented for four selected countries with low to high deforestation and forest degradation rates and illustrate the effect of the inclusion of uncertainties in REDD estimates.

Based on the input data taken from FRA 2010 (FAO, 2010a) Table 3 shows country specific data on the proportional development of the forest area, $\Delta_{\mathrm{BL}}$, and the expected carbon stocks in 2010, $C_{\mathrm{t} 2 \text { real. }}$. These are used to offset them against $\mathrm{C}_{\mathrm{t} 2 \mathrm{BL}}$ in order to achieve the value of the respective emission reductions, $\mathrm{C}_{\mathrm{t} 2 \mathrm{REDD}}$.

\begin{tabular}{|c|c|c|c|c|}
\hline Country & $\Delta_{\mathrm{BL}}(\%)$ & $\mathrm{C}_{\mathrm{t} 2 \mathrm{BL}}(\mathrm{Mt} \mathrm{C})$ & $\mathrm{C}_{\mathrm{t} 2 \text { real }}(\mathrm{Mt} \mathrm{C})$ & $\mathrm{C}_{\mathrm{t} 2 R \mathrm{EDD}}(\mathrm{Mt} \mathrm{C})$ \\
\hline Costa Rica & -7.91 & 199.83 & 236.08 & 38.17 \\
\hline Indonesia & -19.25 & $12,259.50$ & $14,381.84$ & 757.50 \\
\hline Malaysia & -3.64 & $3,428.64$ & $3,360.58$ & -216.64 \\
\hline Madagascar & -4.34 & $1,617.55$ & $1,614.35$ & 8.45 \\
\hline
\end{tabular}

Table 3. Country specific data on $\Delta_{\mathrm{BL}}(\%), \mathrm{C}_{\mathrm{t} 2 \mathrm{BL}}(\mathrm{Mt} \mathrm{C}), \mathrm{C}_{\mathrm{t} 2 \text { real }}(\mathrm{Mt} \mathrm{C}), \mathrm{C}_{\mathrm{t} 2 \mathrm{REDD}}(\mathrm{Mt} \mathrm{C})$

Among the selected countries Malaysia shows the lowest deforestation rate for the reference period $(-3.64 \%)$, while Indonesia's rate is rather high $(-19.25 \%)$. The combination of these proportional figures with the absolute carbon stocks lead to distinct values for the emission reductions. Whereas Madagascar and Costa Rica reached only marginal absolute values of emission reductions (i.e. $8.45 \mathrm{Mt} \mathrm{C}$ and $38.17 \mathrm{Mt} \mathrm{C}$ ), the data by FRA 2010 indicate that 
Indonesia's efforts to reduce deforestation are obviously performing well. The negative value of $\mathrm{C}_{\mathrm{t} 2 \mathrm{REDD}}$ for Malaysia suggests that inconsistent data on carbon stocks in forests have a major influence on the values of emission reductions, and potential activities to reduce deforestation do not result in accountable carbon credits.

Fig. 3 shows the carbon stock development of Costa Rica over time (i.e. 1990, 2000 and 2010) according to the data of the FRA 2010. For the year 2010 the difference of $C_{t 2 r e a l}$ and $C_{t 2 B L}$, i.e. $\mathrm{C}_{\mathrm{t} 2 \mathrm{REDD}}$, is shown in red colour.

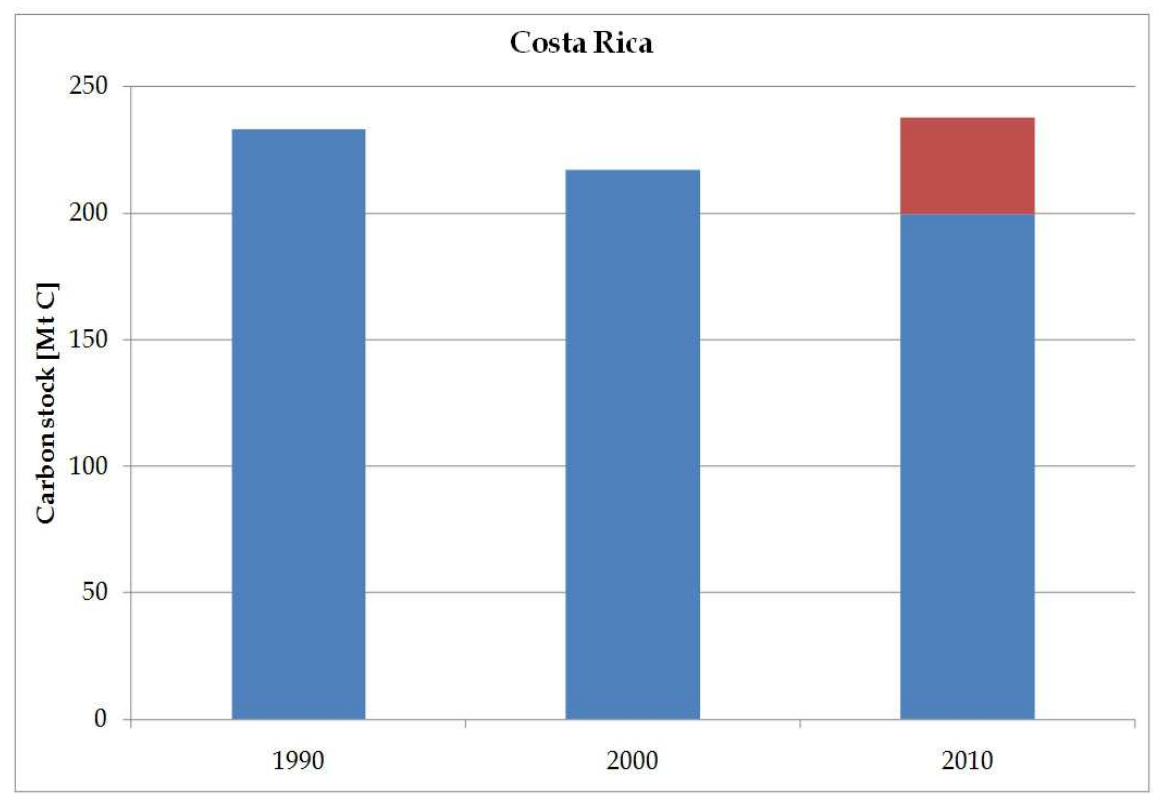

Fig. 3. Carbon stock development over time (i.e. 1990, 2000 and 2010) for Costa Rica; for the year 2010 the difference of $C_{t 2 \text { real }}$ and $C_{t 2 B L}$, i.e. $C_{t 2 R E D D}$, is shown in red colour

For calculating the accountable carbon credits generated by a REDD regime the RME of $\mathrm{C}_{\mathrm{t} 2 \text { real }}$ is used in order to illustrate the effect of uncertainties. Including errors generally reduces the amount of accountable emission reductions. To show the effect of errors, the reliable minimum estimates (RME) of $\mathrm{C}_{\mathrm{t} 2 \text { real }}$ for the four countries were calculated for 0 to $20 \%$ total error. The country specific data on $\mathrm{C}_{\mathrm{t} 2 \mathrm{RME}}$ are shown in Table 4 .

\begin{tabular}{|c|c|c|c|c|c|}
\hline & \multicolumn{5}{|c|}{$\mathrm{C}_{\mathrm{t} 2 \mathrm{RME}}(\mathrm{Mt} \mathrm{C})$} \\
\hline Country / $\mathrm{E}_{\mathrm{t} 2}$ & $0 \%$ & $2 \%$ & $5 \%$ & $10 \%$ & $20 \%$ \\
\hline Costa Rica & 238.00 & 233.24 & 226.10 & 214.20 & 190.40 \\
\hline Indonesia & $13,017.00$ & $12,756.66$ & $12,366.15$ & $11,715.30$ & $10,413.60$ \\
\hline Malaysia & $3,212.00$ & $3,147.76$ & $3,051.40$ & $2,890.80$ & $2,569.60$ \\
\hline Madagascar & $1,626.00$ & $1,593.48$ & $1,544.70$ & $1,463.40$ & $1,300.80$ \\
\hline
\end{tabular}

Table 4. Country specific data on $\mathrm{C}_{\mathrm{t} 2 \mathrm{RME}}(\mathrm{Mt} \mathrm{C})$ 
The decrease of the RME of $\mathrm{C}_{\mathrm{t} 2 \text { real }}$ for higher errors in MRV-systems is obvious for all four countries. While an idealistic total error of $0 \%$ would lead to a $\mathrm{C}_{\mathrm{t} 2 \mathrm{RME}}$ of $13,017 \mathrm{Mt} \mathrm{C}$ for Indonesia, a total error of $20 \%$ would result in about $10,414 \mathrm{Mt} \mathrm{C}$. The respective values were used as reference for calculating the resulting accountable emission reductions, $\hat{\mathrm{C}}_{\mathrm{t} 2 \mathrm{REDD}}$ (Table 5).

\begin{tabular}{|c|c|c|c|c|c|}
\hline & \multicolumn{5}{|c|}{$\hat{\mathrm{C}}_{\text {t2REDD }}(\mathrm{Mt} \mathrm{C})$} \\
\hline Country / $\mathrm{E}_{\mathrm{t} 2}$ & $0 \%$ & $2 \%$ & $5 \%$ & $10 \%$ & $20 \%$ \\
\hline Costa Rica & 38.17 & 33.41 & 26.27 & 14.37 & -9.43 \\
\hline Indonesia & 757.50 & 497.16 & 106.65 & -544.20 & $-1,845.90$ \\
\hline Malaysia & -216.64 & -280.88 & -377.24 & -537.84 & -859.04 \\
\hline Madagascar & 8.45 & -24.07 & -72.85 & -154.15 & -316.75 \\
\hline
\end{tabular}

Table 5. Country specific data on $\hat{\mathrm{C}}_{\mathrm{t} 2 \mathrm{REDD}}(\mathrm{Mt} \mathrm{C})$

Correspondingly, increasing errors decrease the accountable emission reductions, $\hat{\mathrm{C}}_{\mathrm{t} 2 \mathrm{REDD}}$, for all countries. Negative numbers in Table 5 display an increase of $\mathrm{CO}_{2}$ emissions to the atmosphere, positive numbers display $\mathrm{CO}_{2}$ emission reductions. Only the latter would lead to the generation of carbon benefits.

In Fig. 4 the accountable emission reductions are plotted for the four countries over different levels of total error (0 to $20 \%$ ).

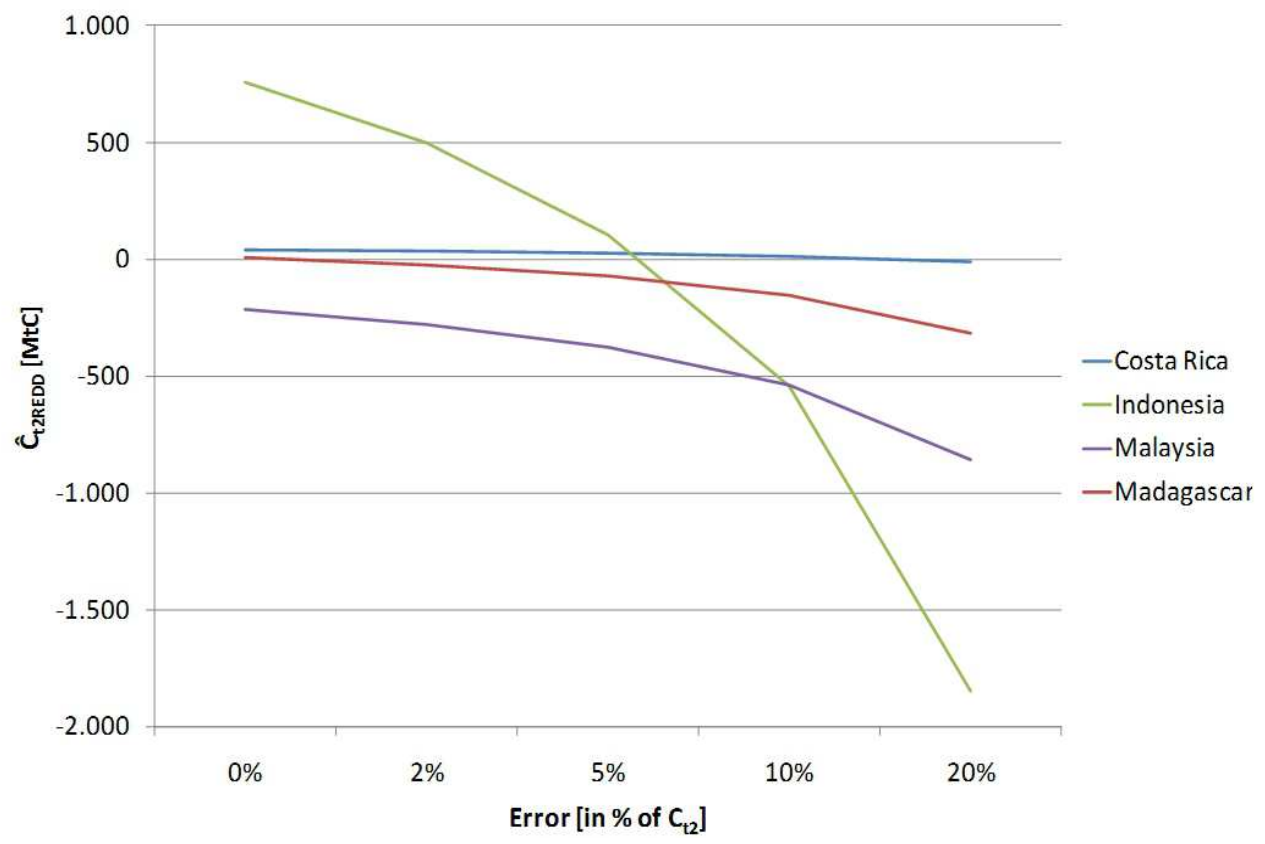

Fig. 4. Influence of total error of a MRV-system on accountable emission reductions 
As large errors jeopardize the generation of accountable carbon credits by REDD, the implementation of a sound MRV-system is decisive for the generation of benefits by the adoption of a REDD regime.

On closer inspection, Fig. 3 shows that even small assessment errors (7\% and less) confound the successful efforts in the reduction of emissions from deforestation and forest degradation. The generation of benefits from REDD is possible only in situations where a robust and transparent MRV-system is applied that results in low total errors associated to carbon estimates. According to studies from Fuller et al. (2003), Gertner and Köhl (1992) or Waggoner (2009) total errors larger than $5 \%$ are most likely to occur.

\section{Conclusion}

In the Eliasch-Review in 2008 it was stated that "Emissions reduction targets can only be monitored effectively if carbon emissions are estimated robustly and uncertainties are managed and quantified." (Eliasch, 2008)

Accordingly, Fig. 5 exemplarily shows the effect of a large total error as a result of a poor MRV-system. The inclusion of the principle of conservativeness through the RME leads to a situation where the carbon stock qualifying for accountable emission reductions is well below the assumed baseline scenario. Under these conditions no credits would be generated, because the country could not prove that it successfully reduced its deforestation and forest degradation rates.

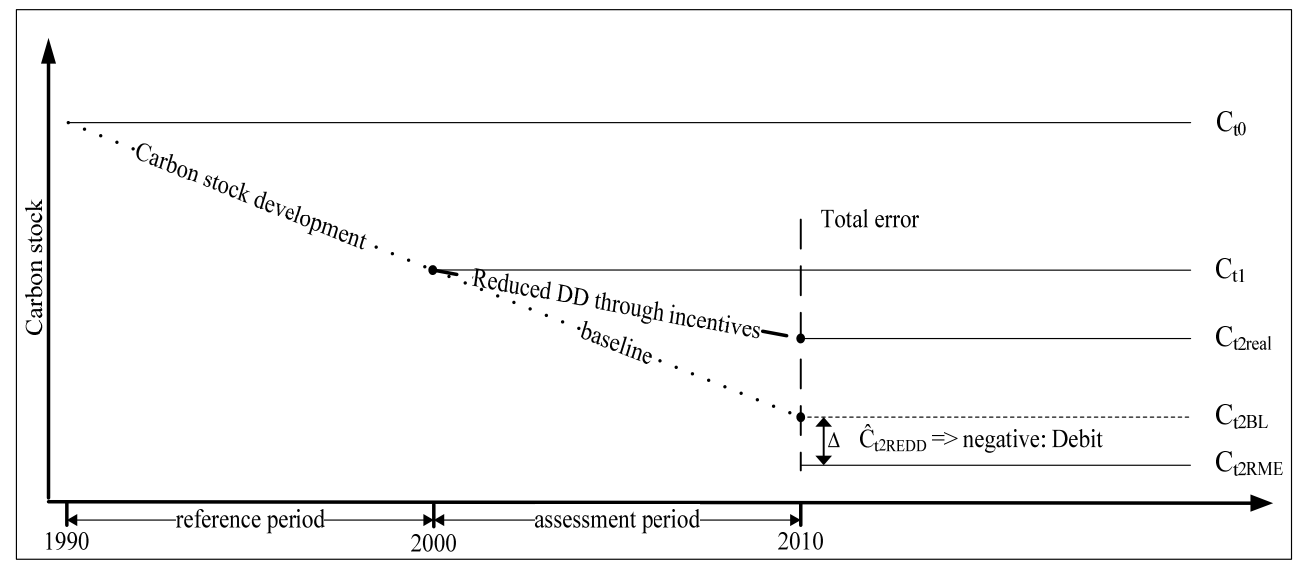

Fig. 5. Reference period (1990 to 2000) and respective carbon stock development for baseline deduction (i.e. difference of carbon stock at $t_{1}, C_{t 1}$, and carbon stock at $t_{0}, C_{t 0}$ ) and relationship of the reduction of deforestation and forest degradation (DD) during the assessment period (2000 to 2010), total error and the respective reliable minimum estimate (RME), and their contribution to the values of the expected carbon stock at $t_{2}$ according to the baseline scenario $\left(\mathrm{C}_{\mathrm{t} 2 \mathrm{BL}}\right)$, real carbon stock at $\mathrm{t}_{2}\left(\mathrm{C}_{\mathrm{t} 2 \text { real }}\right)$, carbon stock at $\mathrm{t}_{2}$ qualifying for accounting $\left(\mathrm{C}_{\mathrm{t} 2 \mathrm{RME}}\right)$ and difference of $\mathrm{C}_{\mathrm{t} 2 \mathrm{BL}}$ and $\mathrm{C}_{\mathrm{t} 2 \mathrm{RME}}\left(\hat{\mathrm{C}}_{\mathrm{t} 2 \mathrm{REDD}}\right)$. A large total error for the MRV-system can result in a negative $\hat{C}_{t 2 R E D D}$ 
The results of the simulation study show that even small errors result in situations where no carbon credits can be generated (Fig. 4). Total errors larger than $7 \%$, which are realistic in extensive forest carbon surveys (Fuller et al., 2003; Gertner \& Köhl; 1992, Waggoner, 2009), may exclude national REDD-regimes from generating benefits.

As shown by theoretical considerations the total error associated with carbon estimates can outweigh efforts to reduce deforestation and forest degradation. This was verified in the simulation study indicating that countries with medium or low deforestation and forest degradation rates are not in a position to generate carbon credits from REDD when the uncertainties of carbon stock estimates are included in calculations as requested in a REDD certification process. Even when a country was successful in reducing carbon losses from deforestation and forest degradation, only a minor amount of carbon credits could be generated or - even worse - emissions from forestry might have to be reported.

A prerequisite for any successful implementation of a REDD regime is the estimation of activity data and emission factors with high reliability, which can be achieved by a robust and transparent MRV-system using appropriate techniques, and comprehensive and internationally consistent approaches (Eliasch, 2008). Special attention needs to be taken to the quantification of the total survey error. A sound assessment and quantification of non-sampling and sampling errors is essential for any REDD inventory concept. We recommend that especially countries in the readiness phase, which have not yet developed appropriate capacities, carefully study the effects of the principle of conservativeness in preparing for REDD. For those countries capacity building for implementing a robust, cost-efficient and transparent MRV-system is urgently needed in order to turn efforts in reducing deforestation and forest degradation into benefits generated by REDD.

\section{Authors' contributions}

Daniel Plugge and Thomas Baldauf equally conceived of the study, performed the statistical analysis, and drafted the manuscript. Michael Köhl participated in the study's design and coordination. This chapter is a revised and updated version of a paper published in 2009 (Köhl et al., 2009).

\section{References}

Baldauf, T., Plugge, D., Rqibate, A., \& Köhl, M. (2009). Case studies on measuring and assessing forest degradation, Monitoring degradation in the scope of REDD, Forest Resource Assessment Working Paper 162.

Dawkins, H. C. (1957). Some results of stratified random sampling of tropical highforest.

Eliasch, J. (2008). Climate change, Financing global forests, the Eliasch review, Earthscan, ISBN 9781844077731, London.

FAO (2010a). Global forest resources assessment 2010, Global Tables, Rome.

FAO (2010b). Global forest resources assessment 2010, Main Report, Rome (FAO forestry paper).

Fuller, R. M., Smith, G. M., \& Devereux, B. J. (2003). The characterisation and measurement of land cover change through remote sensing: problems in operational 
applications? International Journal of Applied Earth Observation and Geoinformation Vol. 4, No. 3, pp. 243-253.

Gertner, G., \& Köhl, M. (1992). An Assessment of Some Nonsampling Errors in a National Survey Using an Error Budget. Forest Science Vol. 38, No. 3, pp. 525$538(14)$.

GOFC-GOLD (2010). A sourcebook of methods and procedures for monitoring and reporting anthropogenic greenhouse gas emissions and removals caused by deforestation, gains and losses of carbon stocks in forests remaining forests, and forestation, a sourcebook of methods and procedures for monitoring, measuring and reporting, GOFC-GOLD Report version COP16-1, Alberta, Canada.

Grassi, G., Monni, S., FEDERICI, S., Achard, F., \& Mollicone, D. (2008). Applying the conservativeness principle to REDD to deal with the uncertainties of the estimates. Environmental Research Letters Vol. 3, No. 3, p. 35005.

Griscom, B., Shoch, D., Stanley, B., Cortez, R., \& Virgilio, N. (2009). Sensitivity of amounts and distribution of tropical forest carbon credits depending on baseline rules. Environmental Science \& Policy Vol. 12, No. 7, pp. 897-911.

Houghton, R., Lawrence, K., Hackler, J., \& Brown, S. (2001). The spatial distribution of forest biomass in the Brazilian Amazon: a comparison of estimates. Global Change Biology Vol. 7, No. 7, pp. 731-746(16).

IPCC (2003). Good practice guidance for land use, land-use change and forestry, IPCC National Greenhouse Gas Inventories Programme, Institute for Global Environmental Strategies (IGES), ISBN 4-88788-003-0, Hayama, Japan.

IPCC (2006). Guidelines for National Greenhouse Gas Inventories, IPCC National Greenhouse Gas Inventories Programme, Institute for Global Environmental Strategies (IGES), ISBN 4-88788-032-4, Japan.

Kish, L. (1965). Survey sampling, Wiley, ISBN 047148900x, New York.

Köhl, M., Baldauf, T., Plugge, D., \& Krug, J. (2009). Reduced emissions from deforestation and forest degradation (REDD): a climate change mitigation strategy on a critical track. Carbon Balance and Management Vol. 4, No 10.

Köhl, M., Magnussen, S., \& Marchetti, M. (2006). Sampling Methods, Remote Sensing and GIS Multiresource Forest Inventory, Springer, ISBN 9783540325727, Berlin, Heidelberg.

Lessler, J. T., \& Kalsbeek, W. D. (1992). Nonsampling error in surveys, Wiley, ISBN 978-0471-86908-5, New York.

Nogueira, E. M., Nelson, B. W., Fearnside, P. M., França, M. B., \& Alves Oliveira, Á. C. de (2008). Tree height in Brazil's 'arc of deforestation': Shorter trees in south and southwest Amazonia imply lower biomass. Forest Ecology and Management Vol. 255, No. 7, pp. 2963-2972.

Plugge, D., Baldauf, T., Rakoto Ratsimba, H., Rajoelison, G., \& Köhl, M. (2010). Combined biomass inventory in the scope of REDD (Reducing Emissions from Deforestation and Forest Degradation). Madagascar Conservation \& Development Vol. 5, No. 1. pp. 23-34.

UNFCCC (2006). Good practice guidance and adjustments under Article 5, paragraph 2, of the Kyoto Protocol, FCCC/KP/CMP/2005/8/Add.3 Decision 20/CMP.1. 
UNFCCC (2006). Modalities and procedures for afforestation and reforestation project activities under the clean development mechanism in the first commitment period of the Kyoto Protocol, Decision 5/CMP.1.

UNFCCC (2008). Reducing emissions from deforestation in developing countries: approaches to stimulate action, FCCC/SBSTA/2008/L.12.

UNFCCC (2011). Report of the Conference of the Parties on its sixteenth session, held in Cancun from 29 November to 10 December 2010, Decisions adopted by the Conference of the Parties, Decision 1/CP.16, 2011-00-27, Available from: http://unfccc.int/resource/docs/2010/cop16/eng/07a01.pdf.

Waggoner, P. E. (2009). Forest Inventories, Discrepancies and Uncertainties. Resources for the Future, Wahington, USA, 2009-00-25, Available from: http://www.rff.org /RFF/Documents/RFF-DP-09-29.pdf. 


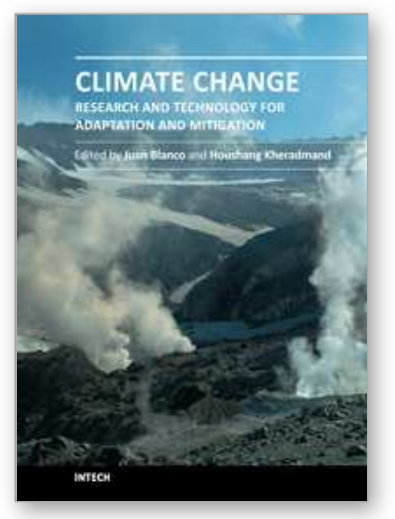

\section{Climate Change - Research and Technology for Adaptation and Mitigation}

Edited by Dr Juan Blanco

ISBN 978-953-307-621-8

Hard cover, 488 pages

Publisher InTech

Published online 06, September, 2011

Published in print edition September, 2011

This book provides an interdisciplinary view of how to prepare the ecological and socio-economic systems to the reality of climate change. Scientifically sound tools are needed to predict its effects on regional, rather than global, scales, as it is the level at which socio-economic plans are designed and natural ecosystem reacts. The first section of this book describes a series of methods and models to downscale the global predictions of climate change, estimate its effects on biophysical systems and monitor the changes as they occur. To reduce the magnitude of these changes, new ways of economic activity must be implemented. The second section of this book explores different options to reduce greenhouse emissions from activities such as forestry, industry and urban development. However, it is becoming increasingly clear that climate change can be minimized, but not avoided, and therefore the socio-economic systems around the world will have to adapt to the new conditions to reduce the adverse impacts to the minimum. The last section of this book explores some options for adaptation.

\section{How to reference}

In order to correctly reference this scholarly work, feel free to copy and paste the following:

Daniel Plugge, Thomas Baldauf and Michael Köhl (2011). Reduced Emissions from Deforestation and Forest Degradation (REDD): Why a Robust and Transparent Monitoring, Reporting and Verification (MRV) System is Mandatory, Climate Change - Research and Technology for Adaptation and Mitigation, Dr Juan Blanco (Ed.), ISBN: 978-953-307-621-8, InTech, Available from: http://www.intechopen.com/books/climate-changeresearch-and-technology-for-adaptation-and-mitigation/reduced-emissions-from-deforestation-and-forestdegradation-redd-why-a-robust-and-transparent-monito

\section{INTECH}

open science | open minds

\section{InTech Europe}

University Campus STeP Ri

Slavka Krautzeka 83/A

51000 Rijeka, Croatia

Phone: +385 (51) 770447

Fax: +385 (51) 686166

www.intechopen.com

\section{InTech China}

Unit 405, Office Block, Hotel Equatorial Shanghai

No.65, Yan An Road (West), Shanghai, 200040, China

中国上海市延安西路65号上海国际贵都大饭店办公楼405单元

Phone: +86-21-62489820

Fax: +86-21-62489821 
(C) 2011 The Author(s). Licensee IntechOpen. This chapter is distributed under the terms of the Creative Commons Attribution-NonCommercialShareAlike-3.0 License, which permits use, distribution and reproduction for non-commercial purposes, provided the original is properly cited and derivative works building on this content are distributed under the same license. 